\title{
Choice and the conditional probability of alternation: Some new data
}

\author{
J. GREGOR FETTERMAN and STANLEY S. PLISKOFF \\ University of Maine, Orono, Maine 04469
}

\begin{abstract}
Three pigeons were exposed to two independent concurrent variable-interval schedules of reinforcement, with a changeover key procedure. Relative reinforcement rate and the fixed-ratio changeover requirement were varied. The effects of these manipulations were assessed with respect to the conditional probability of alternation as a function of successive responses on the same schedule. Previous experiments employing this measure have found essentially unchanging probabilities of alternation. However, we found the probability of alternation to be an increasing function of successive choices of the same schedule, especially with the schedule providing the higher relative reinforcement rate. These findings were discussed with respect to the procedural variables we employed.
\end{abstract}

A recurring issue in the study of choice is the determination of an appropriate behavioral unit (Shimp, 1975). A commitment to a particular behavioral unit, in turn, implicitly reflects the experimenter's presuppositions about the nature of the variables controlling choice. There have emerged two positions that differ fundamentally in their characterizations of choice. According to one view, the molar position (e.g., Baum, 1973), controlling relations exist at the level of largescale aggregations of individual responses and reinforcers. The alternative, the molecular position (e.g., Shimp, 1966), emphasizes a more detailed analysis of the data in its concern with small groups of successive choices and their controlling variables.

To decide between these competing views, researchers have generally employed molecular measures. Their efforts have frequently produced conflicting results, the outcome depending upon the particular molecular measure being studied. Sequential choice data appear to favor molecular processes (e.g., Shimp, 1966), whereas conditional probabilities of alternation between two alternatives do not (e.g., Nevin, 1969).

The variation in the tendency to alternate between available schedules is measured by the conditional probability of alternation (i.e., the conditional probability of changing over from one alternative to a second as a function of successive choices of the first alternative). The molecular position anticipates an increase in this probability, whereas the molar position predicts that it should remain largely invariant. The molar expectation has consistently been supported (Heyman, 1979; Nevin, 1969; Silberberg, Hamilton, Ziriax, \& Casey, 1978).

A rarely addressed facet of this issue is the number of different procedures that have been employed to study it. Since it has become increasingly evident that molar choice statistics are closely tied to procedural variables (e.g., see Baum, 1979; Myers \& Myers, 1977; Pliskoff,
Cicerone, \& Nelson, 1978; Pliskoff \& Fetterman, in press), it may be that molecular measures are affected as well. The present experiment addressed that possibility.

We studied the conditional probability of alternation as the molecular dependent measure. Previous experiments employing this measure differed from the present experiment in several respects. First, with the exception of Nevin's (1969) discrete-trial choice procedure, reinforcers have been made available according to an interdependent scheduling arrangement (Stubbs \& Pliskoff, 1969). We used independent concurrent variable-interval (conc VI) schedules of reinforcement. Second, we used a small fixed-ratio changeover (FR CO) requirement instead of the commonly employed changeover delay (COD). Our interest was in whether these procedural differences would influence the molecular performance variable.

\section{METHOD}

Subjects

Three adult White Carneaux pigeons maintained at $80 \%$ of their free-feeding weights served as subjects. These pigeons all had prior experimental histories.

\footnotetext{
Apparatus

A Lehigh Valley three-key pigeon chamber was used, but the right key was covered. The center and left keys were spaced $7 \mathrm{~cm}$ apart on centers, $22 \mathrm{~cm}$ above the mesh floor of the chamber. The feeder aperture measured $6 \times 6 \mathrm{~cm}$; the bottom of the aperture was $11 \mathrm{~cm}$ above the chamber floor. The animal space measured $35 \times 35 \times 30 \mathrm{~cm}$ (height by width by depth). Ventilation and masking noise were provided by an exhaust fan attached to the chamber. The chamber was housed in a room in which white noise was always present. Electromechanical equipment located in an adjacent room arranged the experimental dependencies and recorded the data.

Procedure

Experimental sessions, conducted 6 days/week, terminated after the pigeon produced 60 reinforcers. A changeover key
} 
Table 1

The Sequence of Experimental Conditions

\begin{tabular}{cccc}
\hline Condition & $\begin{array}{c}\text { Relative } \\
\text { Reinforcement } \\
\text { Rate }\end{array}$ & $\begin{array}{c}\text { CO } \\
\text { Ratio }\end{array}$ & Sessions \\
\hline 1 & .25 & FR 1 & 82 \\
2 & .25 & FR 2 & 39 \\
3 & .75 & FR 2 & 33 \\
4 & .25 & FR 2 & 39 \\
5 & .75 & FR 2 & 60 \\
\hline
\end{tabular}

procedure (Findley, 1958) was used to arrange conc VI schedules of reinforcement. The right (changeover) key could be lit by white light; the left (main) key could be lit by red or green light. Pecks on the changeover key (1) alternated the schedule assignment on and color of the main key and (2) darkened the changeover key and made it inoperative. Following a changeover, the first peck on the main key reactivated and relit the changeover key. If the changeover requirement was FR-2, the first peck on the changeover key darkened the main key and halted the VI programmers. The second peck relit the main key, restarted the programmers, and darkened the changeover key until the first peck on the main key. A peck on the main key produced $3 \mathrm{sec}$ access to food whenever a reinforcer was arranged by the VI schedule associated with that particular main key stimulus.

During all conditions, reinforcers were arranged according to two independent VI schedules. The VI 2-min schedule contained 13 intervals; the VI 6-min schedule contained 10 intervals. The intervals for both schedules were sequenced arithmetically and arranged in a quasirandom order.

Table 1 gives the order of experimental conditions and the number of sessions under each. Nominal relative reinforcement rates are computed with respect to the green key. Table 1 shows that each subject was exposed to two changeover requirements (FR 1 and FR 2) and two relative rates of reinforcement $(.25$ and .75$)$, with one redetermination at each relative reinforcement rate under the FR $2 \mathrm{CO}$ ratio. Each condition of the experiment remained in efrect until performance was stable for 5 days, as judged by eye.

\section{Results}

The number of times each subject pecked once, twice, three times, and so on, successively on the main key in each schedule before alternating was recorded during each session. If, however, 20 or more pecks occurred successively, without interruption by an alternation, the response run was assigned to a "dump" bin. These data were pooled from the last three sessions under each condition. Conditional probabilities of alternation as a function of successive choices of the same schedule were computed from these pooled data. Probabilities were computed only for bins containing 30 or more entries.

Figure 1 shows the conditional probability of alternation as a function of successive pecks to red and green for the five conditions of the experiment, thus yielding two functions for each subject under each condition. The unfilled circles represent successive pecks to red; the filled triangles indicate successive pecks to green. The numbers in parentheses show relative response rate and relative time (represented by the left and right values, respectively). Both behavior measures were computed with respect to the green key. The numbers outside the parentheses refer to the experimental condition (see Table 1). Each row of Figure 1 represents a different subject (Pigeon 9, 4, or 5) under the same condition, and each column shows the five conditions of the experiment for a single subject.

The relation between successive choices and the conditional probability of alternation was, with few exceptions, quite consistent for each subject across the series of conditions. With respect to the schedule providing the higher relative reinforcement rate (red in Conditions 1,2, and 4; green in Conditions 3 and 5), there was an increasing tendency to alternate as the number of successive choices to the main key increased. This trend can be seen in 11 of 15 possible instances ${ }^{1}$ (three subjects, five conditions) and is evidenced by an upward trend in the conditional probability measure as more main key responses were emitted without interruption by an alternation. In the remaining instances, there was

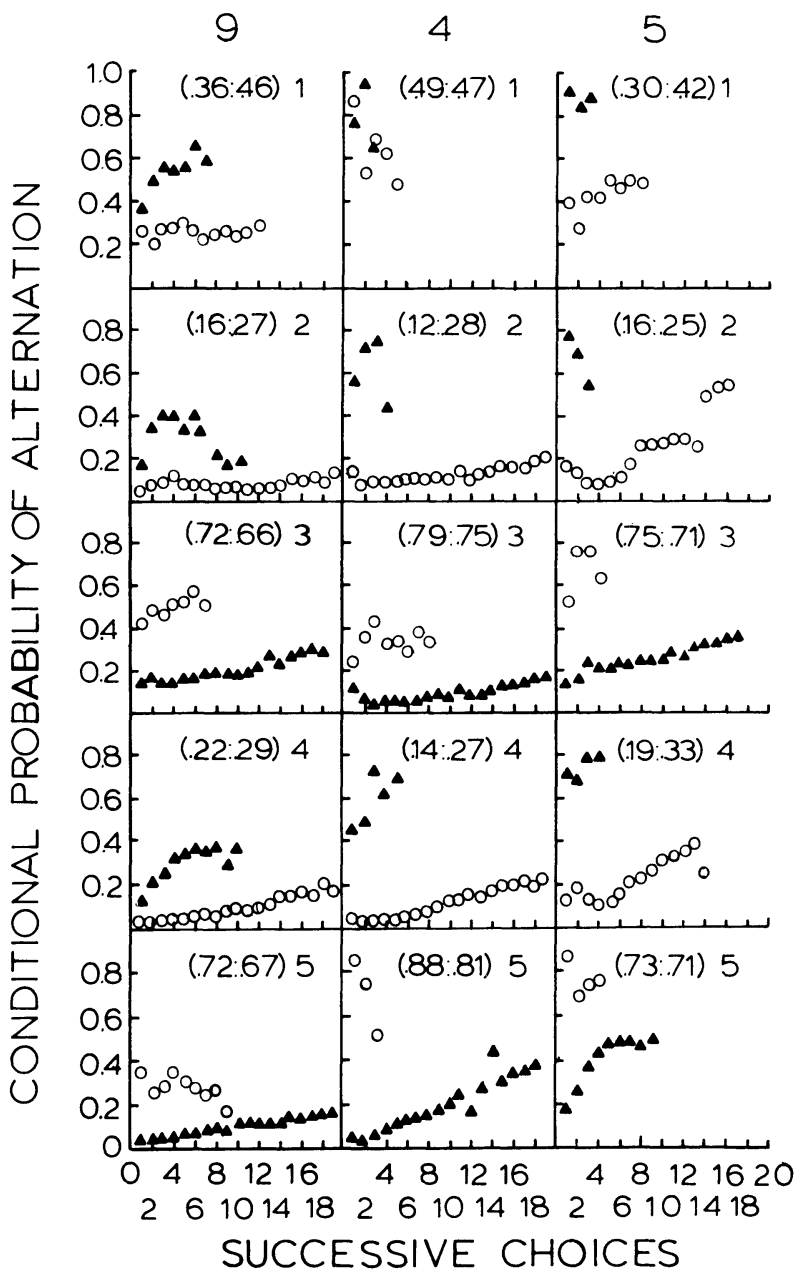

Figure 1. The conditional probability of alternation as a function of successive choices of the same schedule. See text for details. 
no systematic increase or decrease in the probability of alternation.

Regarding the schedule providing the lower relative reinforcement rate (red in Conditions 3 and 5; green in Conditions 1, 2, and 4), there was an increasing tendency toward alternation in 5 of 15 instances. ${ }^{2}$ The remaining cases are different, probably because the number of successive choices to the schedule providing the lower relative reinforcement rate was generally low, often less than five. A striking aspect of those cases was a sharp increase in the probability of alternation from the first to the second response. ${ }^{3}$ In the remaining instances, changeover probabilities were so high following the first response that further increases may have been obscured by a ceiling effect.

When the FR CO requirement was increased from one to two responses (compare Condition 1 with Condition 2), the changes in performance were consistent for all three pigeons. The number of successive choices to the main key uninterrupted by an alternation increased for both schedules, and the conditional probabilities of alternation decreased. Both changes reflect the fact that fewer alternations occurred under the FR 2 CO requirement than under the FR 1.

\section{DISCUSSION}

The main finding of the experiment was that the conditional probability of alternation was (in 16 of 30 instances) an increasing function of successive choices of the same schedule. This trend was more likely to occur in the schedule providing the higher relative reinforcement rate. Our findings stand in contradiction to earlier work employing the same dependent measure (Heyman, 1979; Nevin, 1969; Silberberg et al., 1978).

There are several possible reasons for the findings that may be related to procedural variables. First, and perhaps most important, is the way in which reinforcers were arranged. As was noted earlier, most experiments have used an interdependent scheduling arrangement (Stubbs \& Pliskoff, 1969). We used independent VI schedules. Menlove (1975) has discussed important differences between the two procedures with respect to the local probability of reinforcement for choices immediately following a reinforcer. There are likely other important differences as well (see also Staddon, Hinson, \& Kram, 1981, for a discussion of this issue). The two procedures have often been used interchangeably, the tacit assumption being that approximately equivalent findings at the molar level provide sufficient justification for the substitution (e.g., deVilliers, 1977). The results of the present experiment suggest that this assumption may be unwarranted, as important differences probably exist at the microstructural level.

With specific regard to the conditional probability of alternation measure, the reasoning behind the molecular prediction (an upward trend in the probability) is that there is an increasing probability of reinforcement for a response to the unattended schedule as a function of successive choices of the same schedule. A sensitivity to this change in reinforcement probability implies that the probability of alternation should also increase. It may be that these changes are larger and, therefore, more discriminable with the independent scheduling arrangement. As far as we are aware, this issue has not been addressed experimentally, nor has the more general issue of whether other microstructural differences between the two procedures might exist.
A second procedural variable that may have contribued to the results of the present experiment was the use of the FR CO requirement instead of a COD. Pliskoff et al (1978) found different patterns of mainkey responding, depending upon whether a COD or an FR CO requirement was employed. These differences existed for several seconds following an alternation, and they may account for the present results with respect to the conditional probability of alternation.

The relative contribution of each procedural variable (independent scheduling and the FR CO requirement) is impossible to assess within the context of the present experiment. It is possible that one or both affected the outcome. It is worth noting, however, that Heyman (1979) used a procedure similar to our Condition 1. He employed an FR 1 CO requirement and, under one condition, a relative reinforcement rate of .75. The two experiments differ, though, in the way in which reinforcers were assigned. Heyman used the interdependent procedure, and we used independent scheduling. The results from our Condition 1 are quite different from those reported by Heyman (see his Figure 3).

In summary, it seems likely that, as with molar measures, different findings may be obtained with molecular measures, a given outcome being determined by a host of proceudral variables. Therefore, the use of such measures to justify acceptance or rejection of any model of choice must be viewed with caution.

\section{REFERENCES}

BAUM, W. M. The correlation-based law of effect. Journal of the Experimentat Analysis of Behavior, 1973, 20, 137-153.

BAUM, W. M. Matching, undermatching, and overmatching in studies of choice. Journal of the Experimental Analysis of Behavior, 1979, 32, 269-281.

DEVILLIE RS, P. Choice in concurrent schedules and a quantitative formulation of the law of effect. In W. K. Honig \& J. E. R. Staddon (Eds.), Handbook of operant behavior. New York: Prentice-Hall, 1977.

Findley, J. Preference and switching under concurrent scheduling. Journal of the Experimental Analysis of Behavior, 1958, 1, 123-144.

Heyman, G. A Markov-model description of changeover probabilities on concurrent variable-interval schedules. Journal of the Experimental Analysis of Behavior, 1979, 31, 41-51.

Menlove, R. Local patterns of responding maintained by concurrent and multiple schedules. Journal of the Experimental Analysis of Behavior, 1975, 23, 309-337.

Myers, D., \& MYers, L. Undermatching: A reappraisal of performance on concurrent variable-interval schedules of reinforcement. Journal of the Experimental Analysis of Behavior, 1977, 27, 203-214.

Nevin, J. A. Interval reinforcement of choice behavior in discrete trials. Journal of the Experimental Analysis of Behavior, 1969, 12, 875-885.

Pliskoff, S. S., Cicerone, R., \& Nelson, T. D. Local responserate constancy on concurrent variable-interval schedules of reinforcement. Journal of the Experimental Analysis of Behavior, 1978, 29, 431-446.

Pliskoff, S. S., \& Fetterman, J. G. Undermatching and overmatching: The fixed-ratio changeover requirement. Journal of the Experimental Analysis of Behavior, in press.

Shimp, C. P. Probabilistically reinforced choice behavior in the pigeon. Journal of the Experimental Analysis of Behavior, 1966, 9, 443-455.

Shimp, C. P. Perspectives on the behavioral unit: Choice behavior in animals. In W. K. Estes (Ed.), Handbook of learning and cognitive processes (Vol. 2). Hillsdale, N.J: Erlbaum, 1975. 
Silberberg; A., Hamilton, B., Ziriax, J., \& Casey, J. The structure of choice. Journal of Experimental Psychology: Animal Behavior Processes, 1978, 4, 368-398.

Staddon, J. E. R., Hinson, J. M., \& Kram, R. Optimal choice. Journal of the Experimental Analysis of Behavior, 1981, 35, $397-412$.

StubBs, D. A., \& Pliskoff, S. S. Concurrent responding with fixed relative rate of reinforcement. Journal of the Experimental Analysis of Behavior, 1969, 12, 887-895.

\section{NOTES}

1. Bird 9, Conditions 3, 4, and 5; Bird 4, Conditions 3, 4, and 5; Bird 5, Conditions 1, 2, 3, 4, 5 .

2. Bird 9, Conditions 1, 3, and 4; Bird 4, Conditions 2 and 4.

3. Bird 9, Condition 2; Bird 4, Conditions 1, 2, and 3; Bird 5, Condition 3.

(Received for publication June 1, 1981.)

\section{ERRATUM}

Cogan, D. C., \& Frye, G. L. Learned helplessness: Now you see it, now you don't. Bulletin of the Psychonomic Society, 1981, 17(6), 286-288. Page 288: The authors' names for the Brookshire et al. (1961) reference were incorrectly listed in the text and the reference list as Brookshire, Littleman, and Stewart. The correct reference is as follows:

Brookshire, K. H., Littman, R. A., \& Stewart, C. N. Residue of shock trauma in the white rat: A three factor theory. Psychological Monographs, 1961, 75(10, Whole No. 514). 